\title{
Uso da banda termal do TM/Landsat 5 e NDVI no Mapeamento Digital de Solos do Delta do Parnaíba - Piauí
}

\author{
Use of thermal band of TM/Landsat 5 and NDVI on Digital Soil Mapping of \\ Parnaíba Delta - Piauí
}

AMORIM ${ }^{1}$, J. V. A.; VALLADARES ${ }^{2}$, G. S.; SILVA³ , F. J. L. T.; LEAL ${ }^{4}$, J. M.

amorim1994@hotmail.com

\begin{abstract}
Resumo
O litoral do Piauí apresenta grande diversidade de ecossistemas frágeis e materiais pouco consolidados, onde diversos processos erosivos e de deposição atuam sobre ele, caracterizando um ambiente altamente dinâmico. Além disso, as planícies vegetadas do Delta do Parnaíba apresentam alto valor paisagístico e turístico. Tais fatores justificam o mapeamento dos solos, visando sua conservação e monitoramento. Nessa perspectiva, o presente estudo teve como objetivo mapear os solos do Delta do Parnaíba, através da aplicação de duas variáveis oriundas de uma imagem orbital: banda termal e NDVI. O mapa de temperatura foi confeccionado utilizando as imagens do sensor Thermal Mapper, do satélite Landsat 5. O NDVI foi gerado a partir da razão das bandas vermelha e infravermelho próximo. Os solos foram descritos e coletados em campo por meio da análise de trincheiras, minitrincheiras e tradagens, de acordo com o que preconiza o Sistema Brasileiro de Classificação de Solos. Com base nos resultados, observa-se uma relação entre a cobertura vegetal e a temperatura da superfície, principalmente nas áreas de Planície Flúvio-Marinha e Planície e Terraço Fluvial, onde há predominância de solos com caráter hidromórfico. Ressalta-se que a banda termal e o NDVI mostraram-se atributos promissores no Mapeamento Digital de Solos de ambientes litorâneos.
\end{abstract}

Palavras-chave: Mapeamento de solos; Sensoriamento Remoto; litoral.

\begin{abstract}
The Piauí coast presents a great diversity of fragile ecosystems and little consolidated materials, where several erosive and depositional processes act on it, characterizing a highly dynamic environment. The vegetated plains of the Parnaíba Delta have a high scenic and tourist value. These factors give support to the mapping of soils, aiming at their conservation and monitoring. In this perspective, the present study aimed to map the soils of the Parnaíba Delta, through the application of two variables originating from an orbital image: thermal band and NDVI. The temperature map was created by using the images of the Thermal Mapper sensor of the Landsat 5 satellite. The NDVI was generated from the red and near-infrared bands from the same image. The soils were described and collected in the field through the analysis of trenches, mini-trenches and boreholes, according to the Brazilian Soil Classification System (SiBCS). Based on the results, there is a relation between the vegetation cover and the surface temperature, mainly in the areas of Marine Fluvial Plain and Plain and Fluvial Terrace, where there is predominance of hydromorphic soils. It must be observed that the thermal band and the NDVI showed as promising attributes in the Digital Soil Mapping of coastal environments.
\end{abstract}

Keywords: Soil mapping; Remote Sensing; coast.

\section{INTRODUÇÃO}

No Brasil, os investimentos para o mapeamento e classificação dos solos têm decrescido gradativamente, tendo como uma das principais justificativas os custos elevados. Como consequência, muitos dos levantamentos pedológicos são realizados apenas em escalas de 
reconhecimento e de nível exploratório. Por essa razão poucos pesquisadores e/ou órgãos de pesquisa utilizam mapas de solos para o planejamento (McBRATNEY; MENDONÇA-SANTOS; MINASNY, 2003). Além disso, o número de profissionais capacitados a realizar esses levantamentos vem sendo reduzido a cada ano. Para Höfig (2014), em linhas gerais, a organização de planos de ocupação do solo desconsidera a realidade geomorfológica e pedológica para a execução de um projeto.

Nowatzki (2013) ressalta que a demanda por mapeamentos de solos em escalas mais detalhadas torna-se necessária para embasar os estudos relacionados ao uso sustentável das terras, entre os diversos estudos envolvendo solos. Essa preocupação se dá porque determinados usos do solo contribuem significativamente para a contaminação dos recursos hídricos e, consequentemente, do ambiente, gerando prejuízos econômicos e sociais.

Nesse sentido, com o desenvolvimento das tecnologias e o advento dos Geoprocessamento (GIS Science) nos estudos pedológicos, alternativas para esse impasse surgiram, ressaltando as técnicas de Mapeamento Digital de Solos (MDS). Essas técnicas consistem na aplicação de métodos matemáticos e estatísticos para o estudo da gênese do solo assim como da sua caracterização têmporo-espacial (McBRANTNEY; MINASNY, 2013), tendo em vista a utilização de informações relacionadas à geologia, relevo, hidrografia, clima, vegetação, dentre outras, para a classificação.

Ela visa otimizar tempo e recursos, assim como incrementar os trabalhos convencionais de Pedologia, possibilitando que áreas de maior abrangência sejam mapeadas (NOLASCOCARVALHO; FRANCA-ROCHA; UCHOA, 2009). Além disso, norteia os planos em importantes decisões, como na apropriação de áreas de elevada fragilidade ambiental, a exemplo das zonas costeiras, que se caracterizam pelas mudanças constantes no tempo e alterações no espaço implicando diretamente na sua grande diversidade geológica, geomorfológica, pedológica e paisagística (SOUSA, 2015).

Dessa forma, o estudo a ser realizado tem como foco os tipos de solos presentes no Delta do Parnaíba, zona costeira do estado do Piauí. O Delta está situado na porção norte do litoral piauiense e no nordeste setentrional do Brasil. A paisagem costeira piauiense é constituída por diversos ecossistemas frágeis e materiais pouco consolidados, possuindo uma elevada beleza cênica, onde diversos processos erosivos e de deposição atuam sobre ela, caracterizando, desta forma, um ambiente altamente dinâmico.

Sabendo da importância essencial do estudo das zonas costeiras, e engajados em contribuir com o avanço da ciência do solo, principalmente no estado do Piaú́, o trabalho teve como objetivo mapear as associações de solos existentes no Delta do Parnaíba empregando a imagem da banda 
termal do sensor TM/Landsat 5, bem como o Índice de Vegetação da Diferença Normalizada (NDVI).

\section{METODOLOGIA}

\subsection{Caracterização da área de estudo}

O Delta do Parnaíba está localizado na planície costeira dos estados do Piauí e Maranhão, situada na porção norte do litoral piauiense e no nordeste setentrional do Brasil. Fica a nordeste da costa brasileira, no limite dos estados do Piauí e Maranhão. Encontra-se em uma zona de transição, de acordo com suas condições climáticas e oceanográficas. O rio Parnaíba possui uma moderada descarga de sedimentos em suspenção a qual é principalmente atribuída a geologia e condições climáticas da sua bacia de drenagem (SILVA et al., 2014; SILVA, 2015). O clima da área está enquadrado como do tipo Aw', tropical, com chuvas distribuídas sazonalmente registrando máximas no outono, sendo possível identificar duas estações bem definidas: uma chuvosa durante os primeiros meses do ano, de janeiro a maio, e outra seca que ocorre no segundo semestre, de julho a dezembro.

A área em questão merece destaque pela importância socioeconômica e ambiental que representa para o Estado, tendo em vista a diversidade de ambientes e sistemas naturais que ali se encontram e que subsidiaram atividades econômicas importantes, a exemplo da turística, dentre outras.

Nesse litoral foi criada a Área de Proteção Ambiental Delta do Parnaíba (APA) por meio do Decreto Federal de 28 de agosto de 1996, envolvendo os municípios do Maranhão, Piauí e Ceará, num total de 313.809 hectares e perfazendo um perímetro de $460.812 \mathrm{~m}$, incluindo uma faixa de área marítima. No Piauí a APA abrange parte dos municípios de Parnaíba, Luís Correia, Ilha Grande e Cajueiro da Praia.

Para o desenvolvimento da pesquisa a área selecionada foi a parte oriental do Delta, inserida nos limites do estado do Piauí, de aproximadamente $290 \mathrm{~km}^{2}$. Consiste em uma margem ativa de migração dos campos de dunas, que abrange as florestas de mangue. É delimitada por dois tributários: o rio Parnaíba ao oeste e o rio Igaraçu para o sudeste. Possui praias de até $200 \mathrm{~m}$ de largura e ilhas barreiras, que caracterizam a geomorfologia costeira (SZCZYGIELSKI et al., 2014). A Figura 1 ilustra a localização da área.

De acordo com a geologia, no Delta do Parnaíba predominam sedimentos do período Quaternário. Os sedimentos do período Quartenário são representados pelos depósitos praiais, eólicos, marinhos e lagunares e depósitos colúvio-aluvionares. A área encontra-se subdividida em 
sete unidades geológicas, sendo: Delta e Canais Fluviais; Depósito Litorâneos de Praias Recentes (Q21p); Depósitos Eólicos Litorâneos Móveis (Q2e); Depósitos Eólicos Litorâneos Fixos (Qe); Depósitos fluvioaluvionares (Qfa); Depósitos de Pântanos e Mangues (Qpm); e Depósitos arenosos (Qd) (VALLADARES; CABRAL, 2017).

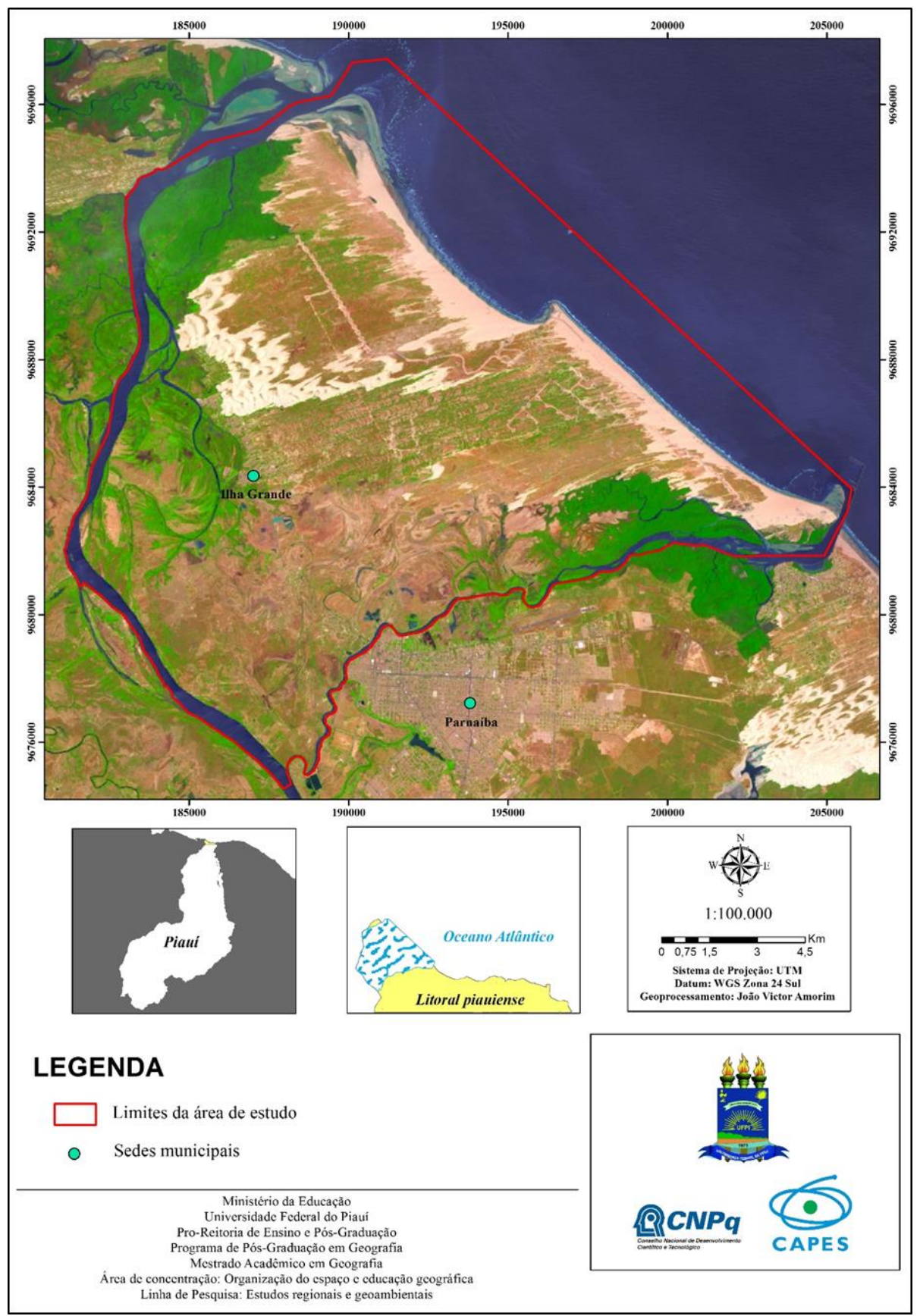

Figura 01: Localização da área de estudo. Fonte: U.S. Geological Survey (2017), adaptado pelos autores.

As unidades geomorfológicas que compõem a área em estudo compreendem os relevos de agradação. Os relevos de agradação são aqueles em que predominam os processos deposicionais, tanto do tipo continental como é o exemplo da planície fluvial, quanto do tipo litorâneo como é o 
caso da planície costeira, da planície fluvio-marinha, das planícies coluvio-aluvio-marinhas e as planícies flúvio-lagunares, além de dunas móveis, cordão arenoso e praias.

No mapeamento realizado por Sousa (2015), em escala de 1:100.000 é possível identificar 9 (nove) unidades geomorfológicas na área de Delta do Parnaíba, sendo: Cordão arenoso; Delta e canais fluviais; Dunas estabilizadas; Dunas móveis; Paleodunas; Praia; Planície eólica; Planície fluvio-marinha e; Planície e terraço fluvial (Figura 2).

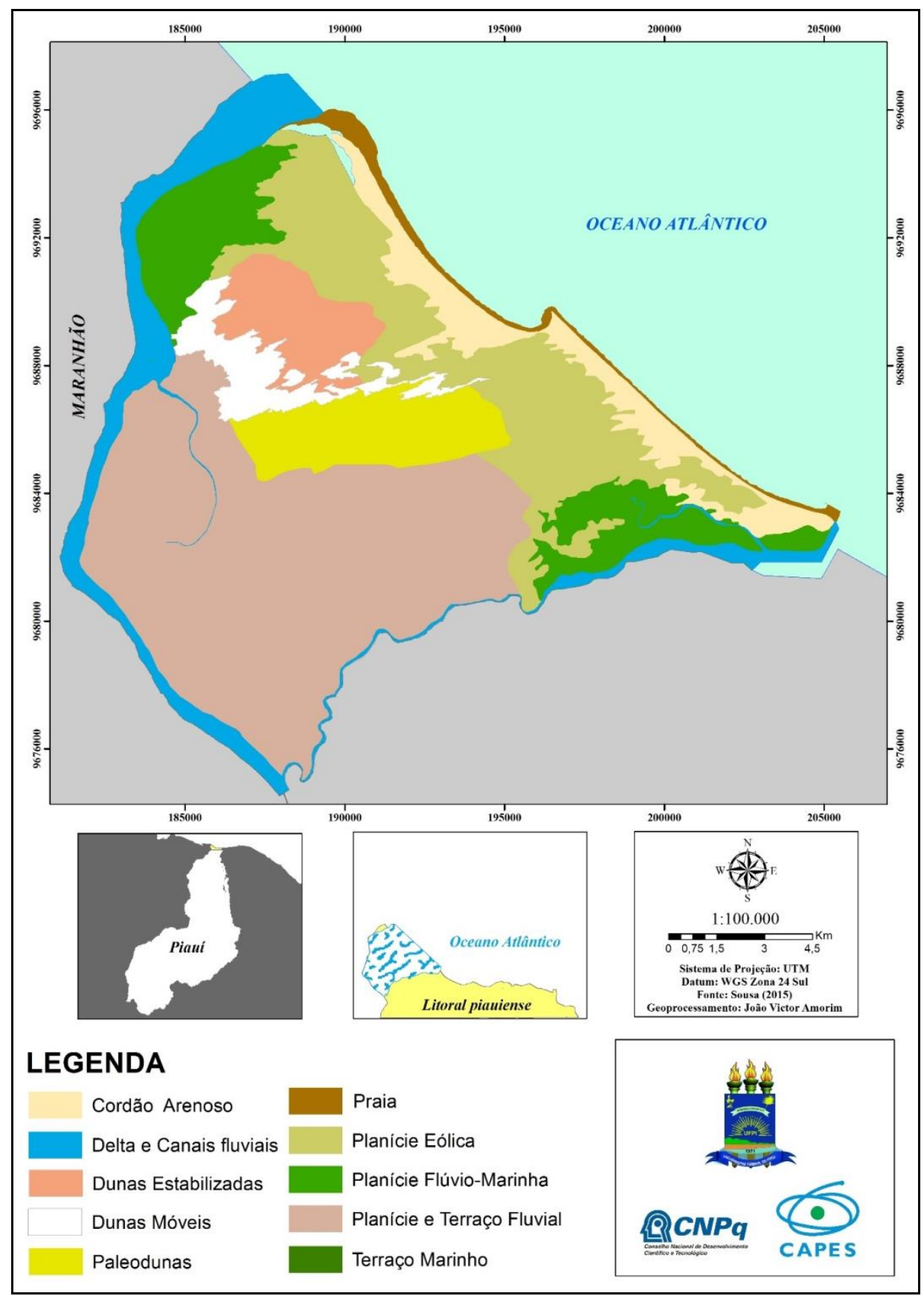

Figura 2: Mapa das Unidades Geomorfologicas do Delta do Parnaíba. Fonte: Sousa (2015), adaptado pelos autores. 
Em relação aos aspectos vegetacionais, embasado no Mapeamento da Cobertura das Terras realizado em escala de 1:40.000, foi possível identificar 5 (cinco) tipos de vegetação na área, sendo: Vegetação Arbórea Arbustiva; Vegetação Arbustiva Densa; Vegetação de Mangue; Vegetação Paludosa e Vegetação Rasteira (AMORIM, 2017). A vegetação da planície costeira piauiense se desenvolve, principalmente, na praia, nas dunas, nas áreas de mangues, ao longo dos cursos de água e nos tabuleiros, apresentando diferenciações decorrentes das variações na composição edáfica e profundidade do lençol freático (CAVALCANTI, 1996).

\subsection{Materiais e procedimentos metodológicos}

Para alcance do objetivo proposto, os materiais utilizados consistiram em produtos de Sensoriamento Remoto e ferramentas de campo. No que diz respeito aos produtos de Sensoriamento Remoto, decidiu-se pela utilização das imagens orbitais do satélite Landsat 5 Thematic Mapper (TM), obtida em 12 de novembro de 2010 e sob o sistema de coordenadas Universal Transversa de Mercator (UTM), Datum WGS 1984 Zona 24 Sul, para visualização dos alvos na superfície terrestre. As ferramentas de campo, para coleta de perfis de solo, foram: Trado holandês; Pá reta; Enxada e enxadão; Martelo; Faca e Carta de cores Munsell (MUNSELL SOIL-COLOR CHARTS, 2009).

Para caracterização dos solos foram coletados 41 (quarenta e um) perfis de solo. Os solos foram caracterizados segundo o Manual de Descrição e Coleta de Solo no Campo de Lemos e Santos (1996) e Santos et al. (2015) e do Sistema Brasileiro de Classificação dos Solos - SiBCS (Santos et al., 2013). As amostras, após a coleta, foram secas e peneiradas (2 mm), constituindo a terra fina seca ao ar (TFSA).

Na TFSA, os atributos físicos e químicos foram determinados de acordo com as orientações do Manual de Métodos de Análise de Solos da EMBRAPA (DONAGEMA et al., 2011). As análises físicas realizadas consistiram em: densidade aparente (Ds), realizada através do método do anel volumétrico, com anel de $50 \mathrm{~cm}^{3}$ de volume; e análise granulométrica (areia, silte, argila)/dispersão total, avaliada pelo método da pipeta, usando-se dispersão com $\mathrm{NaOH} 1 \mathrm{~mol} \mathrm{~L}^{-1}$.

No que tange as análises químicas, o pH foi determinado em água; carbono orgânico, por oxidação da matéria orgânica via úmida com $\mathrm{K}^{2} \mathrm{Cr}^{2} \mathrm{O}^{7}$ em meio sulfúrico; $\mathrm{Ca}^{2+}, \mathrm{Mg}^{2+}$ e $\mathrm{Al}^{3+}$ utilizando solução extratora de $\mathrm{KCl} ; \mathrm{Na}^{+}, \mathrm{K}^{+}$e $\mathrm{P}$ assimilável pelo método de Mehlich; acidez total $(\mathrm{Al} 3++\mathrm{H}+)$; e condutividade elétrica, efetivada por meio do método de condutividade elétrica do extrato aquoso. A partir dos atributos morfológicos e dos dados de análises físicas e químicas, os perfis de solo foram classificados de acordo o SiBCS. 
Para o mapeamento das associações de solo com base na imagem Landsat, foi empregada a banda 6 do Landsat TM 5, órbita/ponto 219/062, conhecida como banda termal, na faixa do infravermelho, com comprimento de onda de 10,4 a 12,5 $\mu \mathrm{m}$, sem efetuar nenhuma transformação na imagem.

Além disso, foi utilizado o NDVI. Para Chagas (2006) os índices de vegetação são medidas quantitativas que tentam medir a biomassa ou vigor da vegetação. Usualmente, são formados a partir da combinação de vários valores espectrais que são somados, divididos ou multiplicados de modo a produzir um único valor que indica a quantidade ou vigor da vegetação dentro de um pixel.

Nesse sentido, para a imagem do sensor TM do Landsat $5 \mathrm{o}$ índice NDVI foi obtido a partir do cálculo das bandas 3 e 4 do Landsat TM5, conhecidas como banda do visível-vermelho e infravermelho próximo com comprimento de onda de 0,63 a $0,69 \mu \mathrm{m}$ e 0,76 a $0,90 \mu \mathrm{m}$ respectivamente, e resolução espacial de $30 \mathrm{~m}$. A fórmula utilizada foi a seguinte:

$$
\mathrm{NDVI}=(\mathrm{IVP}-\mathrm{V}) /(\mathrm{IVP}+\mathrm{V})
$$

onde: IVP = infravermelho próximo e V= vermelho.

\section{RESULTADOS E DISCUSSÃO}

A imagem proveniente da banda termal apresentou pixels com variação, para a área de estudo, de 121 a 159, com distribuição bimodal (Figura 3). A banda termal do satélite Landsat-5, sensor TM permite, remotamente, a obtenção da estimativa da temperatura do solo por meio da transformação do número digital da imagem (ND) em radiância (MORAES et al., 2013).

Os pixels com valores entre 125 e 137 classificaram as áreas de Planície Flúvio-Marinha, sendo possível encontrar associações principalmente de GLEISSOLO TIOMÓRFICO + GLEISSOLO SÁLICO + GLEISSOLO MELÂNICO + ORGANOSSOLO TIOMÓRFICO, todos de textura argilosa ou indiscriminada. Valores entre 137 e 142 indicaram áreas onde houve maior reflectância da luz na passagem do sensor. Podem-se associar essas áreas a terrenos de Dunas Móveis, Cordão arenoso e praia, sendo possível identificar NEOSSOLO QUARTZARÊNICO + DUNAS MÓVEIS + ESPODOSSOLO HUMILÚVICO, todos de textura arenosa.

Valores de pixels de 142 a 146 foram capazes de classificar parcialmente áreas de Planície Eólica, Dunas estabilizadas e Paleodunas. Nessas áreas encontram-se principalmente NEOSSOLOS QUARTZARÊNICOS. Os valores de pixel de 146 a 159 representam áreas de Planície e Terraço 
Fluvial com associações principalmente de PLANOSSOLO NÁTRICO + PLANOSSOLO HÁPLICO + NEOSSOLO FLÚVICO + VERTISSOLO HÁPLICO.

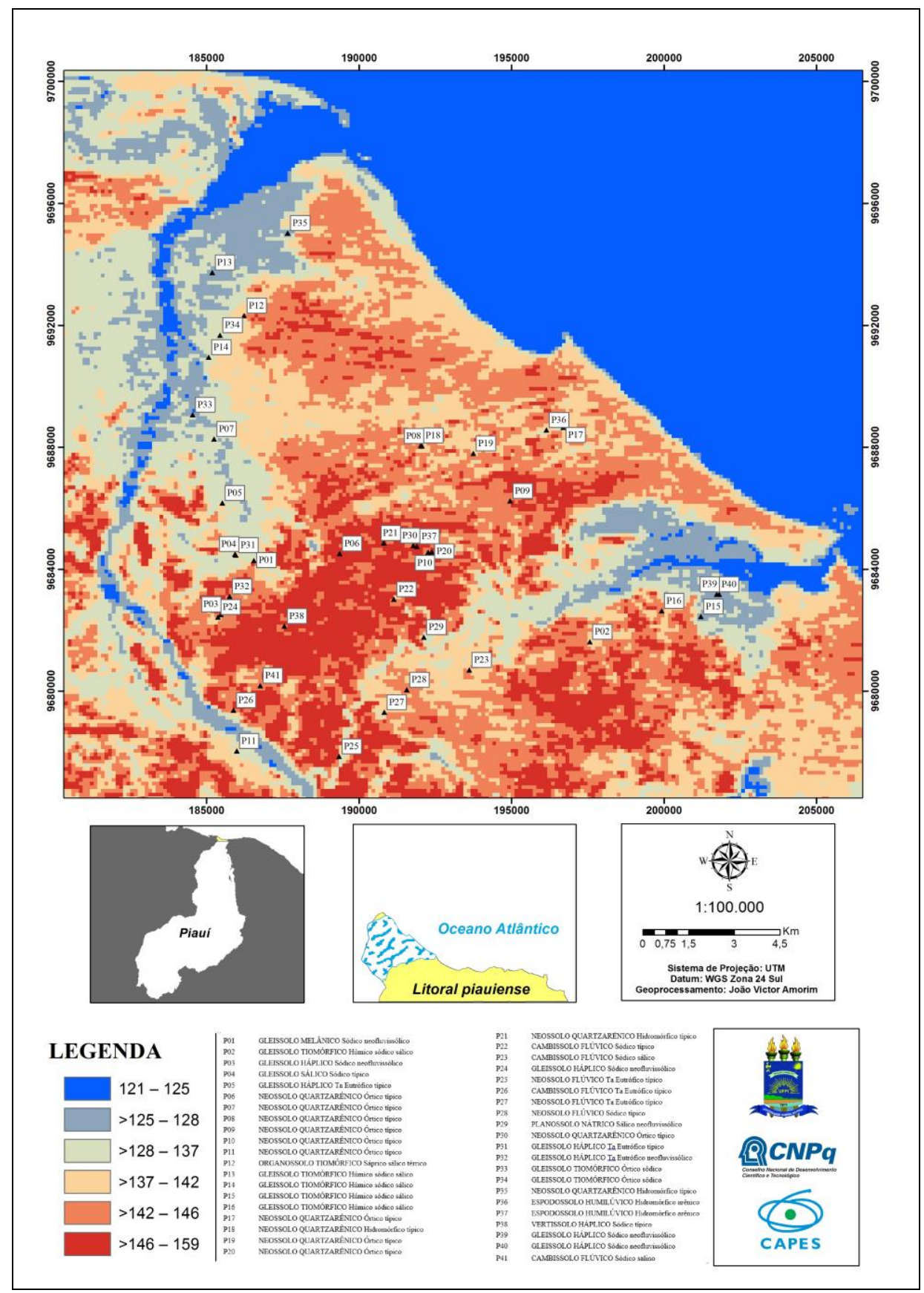

Figura 3: Banda termal do sensor TM do Landsat 5 (órbita/ponto 219/062). Fonte: INPE (2010), adaptado pelos autores.

$\mathrm{Na}$ imagem resultante do NDVI, o coeficiente calculado varia em uma escala compreendida entre -1 e +1 , quanto mais próximo de -1 menor será o índice de vegetação e quanto mais próximo de 1 maior será o índice de vegetação (Figura 4). 
Para a banda Landsat na região do vermelho $(\mathrm{V})$, a vegetação verde, densa e uniforme fica escura. Por outro lado, para a banda infravermelho (NIR), os corpos d'água ficam escuros e a vegetação verde, densa e uniforme fica clara. Disto resulta uma nova banda espectral, representando a razão entre as bandas originais, onde as áreas claras indicam a presença de vegetação e as áreas escuras, sua ausência (FREIRE; PACHECO, 2005).

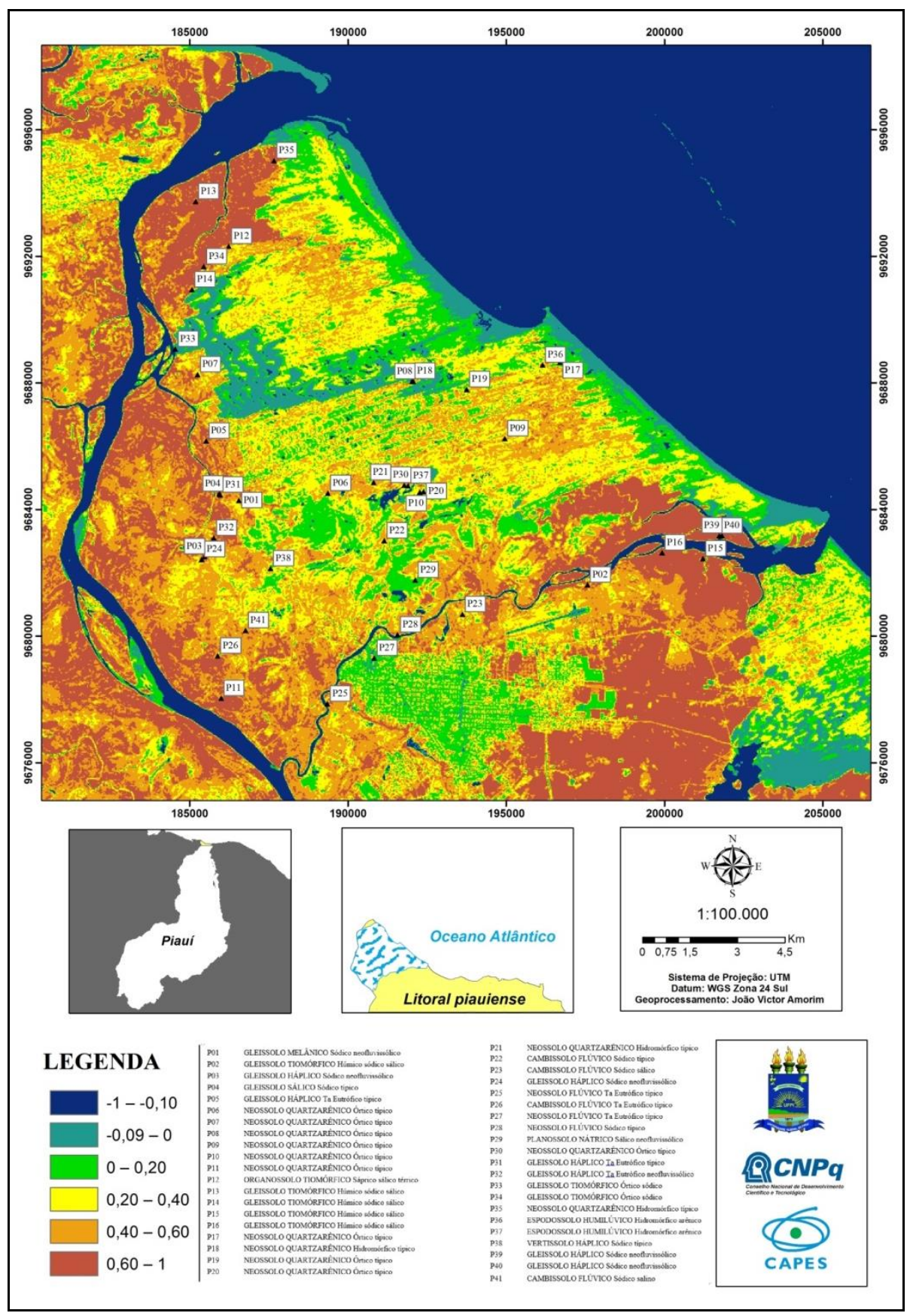

Figura 4: Índice de Vegetação da Diferença Normalizada/TM Landsat 5 (razão de bandas: NIR/V). Fonte: INPE (2010), adaptado pelos autores. 
$\mathrm{Na}$ área de estudo os valores digitais dos pixels entre -1 e - -0,10 indicaram corpos d’água. Os pixels com valores de $-0,09$ a 0 indicam áreas com baixa resposta espectral da vegetação. Essas áreas correspondem a Dunas Móveis, Cordão arenoso e praia, constituídos predominantemente por materiais arenosos pouco consolidados, sendo encontradas associações de NEOSSOLO QUARTZARÊNICO + DUNAS MÓVEIS + ESPODOSSOLO HUMILÚVICO. Valores de pixel de 0 a 0,20 representam as áreas onde há a presença de vegetação rasteira herbácea e/ou arbustiva, estando associado a ela, principalmente NEOSSOLO QUARTZARÊNICO + PLANOSSOLO NÁTRICO + CAMBISSOLO FLÚVICO.

Pixels com valores entre 0,20 a 0,40 classificaram as áreas de campos naturais abertos. Nessas áreas há o predomínio de espécies herbáceas e/ou arbustivas, como a Scoparia dulcis L. (Vassourinha) (GUZZI, 2012) e é comum encontrar corpos d'água devido à baixa posição no relevo e proximidade do lençol freático à superfície, podendo ocorrer solos de textura arenosa e com forte restrição à drenagem (NEOSSOLO QUARTZARÊNICO Hidromórfico). A Figura 5 ilustra campos alagadiços/mal drenados na área.

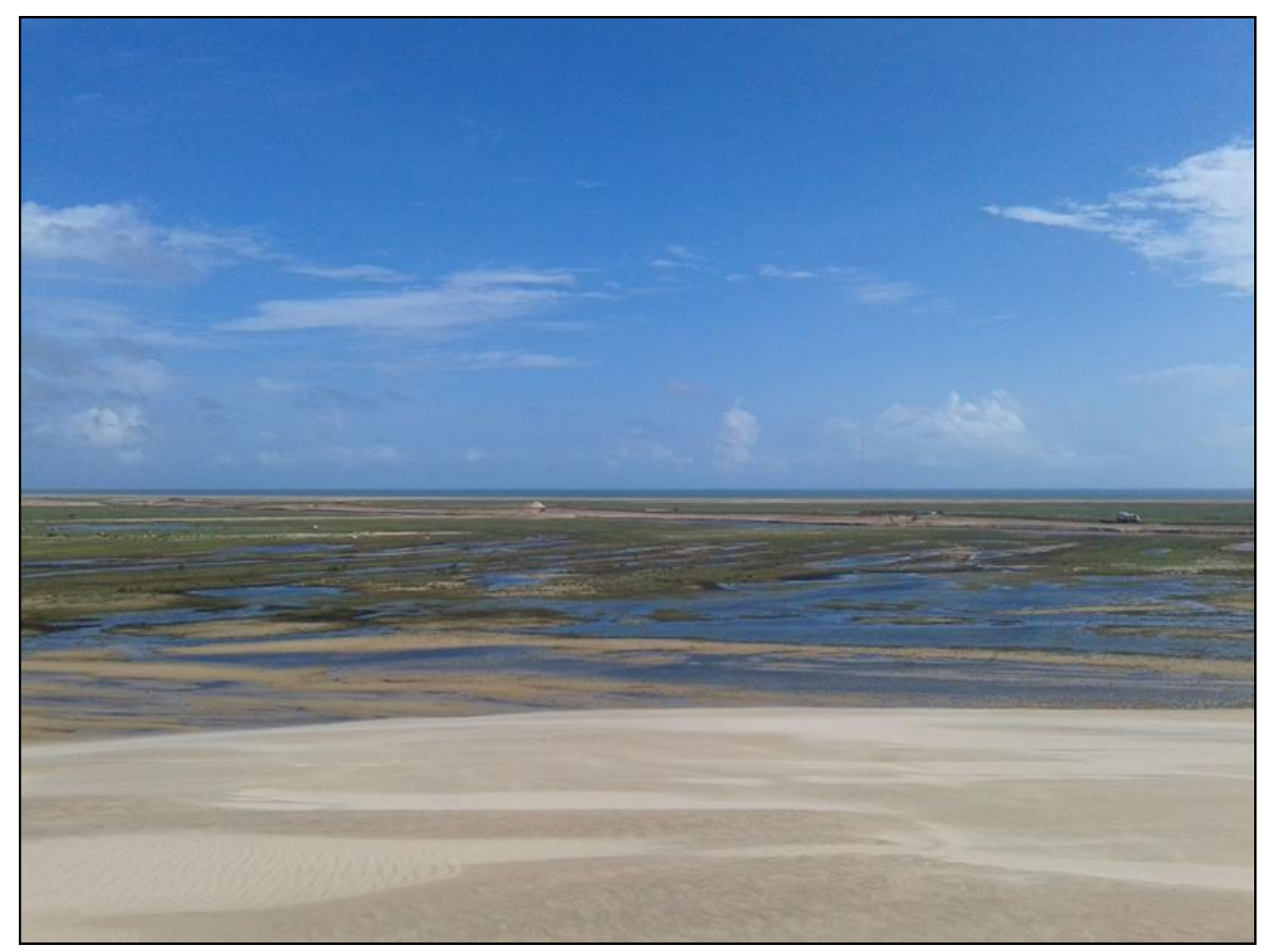

Figura 5: Campos inundados no Delta do Parnaíba - Piauí. Fonte: Amorim (2017). 
Valores de pixel de 0,40 a 0,60 indicam áreas com predomínio de vegetação de porte mais arbustivo/arbóreo, ressaltando-se a ocorrência de espécies do tipo Machaerium Iunatum (Jiquiriti), Croton adenocalyx Baill (Caatinga-branca), Combretum laxum Jacq. (Mufumbo), dentre outras.

Interpretando os valores de 0,60 a 1, podem-se classificar as áreas de planícies flúviomarinha, com vegetação arbórea densa de mangue e vegetação paludosa (vegetação próxima às margens dos rios, associada a planícies de inundação), resultando em alta resposta espectral. Nessas áreas ocorrem principalmente associações de GLEISSOLO SÁLICO + GLEISSOLO HÁPLICO + GLEISSOLO TIOMÓRFICO + GLEISSOLO MELÂNICO + ORGANOSSOLO TIOMÓRFICO.

\section{CONSIDERAÇÕES FINAIS}

Embora com limites não nitidamente delimitados, ressalta-se que os produtos oriundos da imagem Landsat 5 TM (banda termal e NDVI), na data estudada, mostraram-se atributos convenientes, quando analisados concomitantemente, para o MDS da área, sendo possível associar as classes geradas com a ocorrência de alguns solos.

\section{REFERÊNCIAS}

AMORIM, João Victor Alves. Uso e cobertura das terras e áreas potenciais para o turismo no Delta do Parnaíba - Piauí. Monografia (Licenciatura em Geografia) - Coordenação do Curso de Geografia, Universidade Federal do Piauí, Teresina, 2017, 76p.

CAVALCANTI, A. P. B. Impactos e condições ambientais da zona costeira do Estado do Piaú. Tese (Doutorado). Programa de Pós-Graduação em Geografia, Universidade Estadual Paulista UNESP, Rio Claro, 2000, 356p.

CAVALCANTI, Agostinho Paula Brito. Caracterização e análise das unidades geoambientais na planície deltaica do rio Parnaíba / PI. (Dissertação) Metrado. Programa de Pós-Graduação em Geografia, Universidade Estadual Paulista - Rio Claro, 1996.

CHAGAS, C. S. Mapeamento digital de solos por correlação ambiental e redes neurais em uma bacia hidrográfica no domínio de mar de morros. Tese (Doutorado) - Universidade Federal de Viçosa, Viçosa, 2006, 223p.

DONAGEMA, G. K.; CAMPOS, D. V. B. de; CALDERANO, S. B.; TEIXEIRA, W. G.; VIANA, J. H. M. (Org.). Manual de métodos de análise de solos. Rio de Janeiro: Embrapa Solos, 2011.

EMBRAPA (Empresa Brasileira de Pesquisa Agropecuária). Centro Nacional de Pesquisa de Solos. Sistema Brasileiro de Classificação de Solos. 3. ed. Brasília, 2013. 
FREIRE, N. C.F, PACHECO, A. P. Aspectos da detecção de áreas de risco à desertificação na região de Xingó. XII. In SIMPÓSIO BRASILEIRO DE SENSORIAMENTO REMOTO. Anais... Goiânia, Brasil, 2005.

GUZZI, Anderson. Biodiversidade do Delta do Parnaíba: litoral piauiense. Parnaíba : EDUFPI, 2012.

HÖFIG, Pedro. Mapeamento Digital de Solos e o Mapa de Solos como ferramenta para classificação de aptidão de uso das terras. Dissertação (Mestrado em Agronomia - Programa de Pós-Graduação em Ciência do Solo - Universidade Federal do Rio Grande do Sul), Porto Alegre, 2014, 90p.

LEMOS, Raimundo Costa de; SANTOS, Raphael David dos. Manual de Descrição de Coleta de Solo no Campo, 3. ed, Campinas : Sociedade Brasileira de Ciência do Solo, 1996.

McBRANTNEY. A. B.; MINASNY, B. Pedometria: motivação, história e aplicações (palestra). In: CONGRESSO BRASILEIRO DE CIÊNCIA DO SOLO, 34, Florianópolis, SC, 2013.

McBRATNEY, A. B.; MENDONÇA-SANTOS, M. L.; MINASNY, B. On digital soilmapping. Geoderma, v. 117, p. 3-52, 2003.

MORAES, D. A. C.; SARTORI, A. A. C.; HOLLER, W. A.; SPADOTTO, C. A.; MARTINHO, P. R. R.; ZIMBACK, C. R. L. Uso da banda termal do satélite LANDSAT-5 e técnicas de geoestatística na estimativa da degradação da Atrazina no solo da Área de Proteção Ambiental de Tejupá. Simpósio de Geoestatística Aplicada em Ciências Agrárias, 3. In Anais... Botucatu, SP, 2013.

MUNSELL COLOR COMPANY. Munsell soil-color charts, 2009.

NOLASCO-CARVALHO, Claudia C.; FRANCA-ROCHA, Washington; UCHOA, José M. Mapa digital de solos: Uma proposta metodológica usando inferência fuzzy. Revista Brasileira de Engenharia Agrícola e Ambiental, v.13, n.1, p.46-55, 2009.

NOWATZKI, Alexei. Utilização de atributos topográficos no mapeamento preliminar de solos da bacia hidrográfica do rio Pequeno (Antonina/PR). Dissertação (Mestrado em Geografia). Departamento de Geografia, Setor de Ciências da Terra, Universidade Federal do Paraná, Curitiba, 2013, 113p.

SANTOS, Raphael David dos; SANTOS, Humberto Gonçalves dos; KER, João Carlos; ANJOS, Lúcia Helena Cunha dos; SHIMIZU, Sérgio Hideiti. Manual de descrição e coleta de solo no campo. 7. ed. Viçosa, MG : Sociedade Brasileira de Ciência do Solo, 2015.

SILVA, André G. Aquino da. The parnaíba river delta - from modern hydro and morphodynamics to sea level change. Dissertation: ZurErlangung des Doktorgrades der Mathematisch-NaturwissenschaftlichenFakultät der Christian-Albrechts-Universität, Kiel, 2015.

SILVA, André G. Aquino da; STATTEGGER, Karl; SCHWARZER, Klaus; VITAL, Helenice; HEISE, Bjorn. The Influence of Climatic Variations on River Delta Hydrodynamics and Morphodynamics in the Parnaíba Delta, Brazil. Journal of Coastal Research, Coconut Creek, Florida, DOI: 10.2112/JCOASTRES-D-14-00078.1, p. 1-10, 2014. 
SOUSA, Roneide dos Santos. Planície Costeira do Estado do Piauí: mapeamento das unidades de paisagem, uso e cobertura da terra e vulnerabilidade ambiental. Dissertação (Mestrado em Geografia - Programa de Pós Graduação em Geografia, Universidade Federal do Piauí), Teresina, 2015, 138p.

SZCZYGIELSKI, Agata; STATTEGGER, Karl; SCHWARZER, Klaus; SILVA, André G. Aquino da.; VITAL, Helenice; KOENING, Juliane. Evolution of the Parnaíba Delta (NE Brazil) during the late Holocene. Geo-Mar Lett, v. 35, n. 2,DOI 10.1007/s00367-014-0395-x, Springer-Verlag Berlin Heidelberg, p.105-117, 2014.

VALLADARES, Gustavo Souza; CABRAL, L. J. R. S. Mapeamento geológico da Planície do Delta do Parnaíba-PI. SIMPOSIO DE GEOLOGIA DO NORDESTE, 27. In Anais... João Pessoa, PB, 2017.

\section{AGRADECIMENTOS}

Ao Conselho Nacional de Desenvolvimento Científico e Tecnológico (CNPq) pela aprovação e financiamento do projeto de pesquisa intitulado "Paisagem Costeira do Piauí", o qual parte dos resultados balizou a construção do presente manuscrito.

Recebido em: 06/08/2019

Aceito para publicação em: 05/10/2019 